\begin{tabular}{llllllllll}
\hline $\mathrm{C}$ & $\mathrm{O}$ & $\mathrm{M}$ & $\mathrm{M}$ & $\mathrm{E}$ & $\mathrm{N}$ & $\mathrm{T}$ & $\mathrm{A}$ & $\mathrm{R}$ & $\mathrm{Y}$ \\
\hline
\end{tabular}

\title{
Harm Reduction and Illegal Drugs: The Real Debate
}

\author{
Colin Mangham, PhD
}

We are familiar with harm reduction as a subset of our drug response, aimed at reducing immediate harms among heavy users and addicted persons. ${ }^{1}$ However, today many parties are promoting harm reduction as a new ensign for national and provincial drug policies. Its advocates promote a liberalized view of drugs, and changes in drug laws. ${ }^{2,3}$ This promotion is not following a process of open debate.

Harm reduction advocates advance three overlapping and convoluted arguments: 1) that the main reason drugs are illegal is a "moral panic," that drug laws cause more problems than do drugs themselves, ${ }^{4,5}$ and that a "values neutral" (i.e., harm reduction) approach will rectify this; 2) that harm reduction is compassionate while status quo approaches label drug users as deficient or deviant; ${ }^{6}$ and 3 ) that since people have always used drugs, harm reduction provides the only practical answer. ${ }^{3,4}$ In my view, each argument has serious problems.

First, there is no such thing as values neutral. Our only choice is to declare what collective values we desire to convey. Harm reduction proposes values suggesting that drug use is acceptable and unavoidable and that largely, drug laws themselves cause the problem. ${ }^{4,5}$ Supply reduction and demand reduction - the core of Canada's Drug Strategy $^{7}$ - rest on values suggesting that illegal drug use robs people of dignity and self-respect, produce deeply negative

Director, Prevention Source BC, Vancouver, BC; Faculty Associate, Institute for Health Promotion Research, University of British Columbia, Vancouver, BC; Adjunct Professor, School of Human Health and Performance, Dalhousie University, Halifax, NS

Correspondence: Dr. Colin Mangham, Director, Prevention Source BC, \#210 - 2730 Commercial Drive, Vancouver, BC V5N 5P4, Tel: 604-8748452, E-mail: colinm@preventionsource.bc.ca

The views expressed herein are entirely those of the author, and do not reflect BC Government or Prevention Source BC Policy. impacts, and should not receive society's stamp of approval, even tacitly.

Second, harm reduction claims, but lacks, compassion. Drugs entrap and hurt individuals and families, and waste potential. Genuine compassion means doing whatever it takes to help individuals get off drugs, full stop.

Third, by assuming that drug laws create many or most problems with drugs and that drug use is unavoidable, proponents of harm reduction would shift responsibility off of drug users and the drug industry and onto the rest of society. With harm reduction, we lower our social and cultural aspirations to a common denominator determined by the very small percentage of society who use illegal drugs.

Fourth, by assuming that all we can really do is help people use drugs "wisely and well," ${ }^{8}$ harm reduction diminishes primary prevention. It ignores the fact that drug use rises and falls with social acceptance and availability, both of which are changeable as we have witnessed with both tobacco use and drinking and driving. ${ }^{9,10}$ Harm reduction advocates accuse prevention advocates of treating drug users as deviant or deficient. ${ }^{6}$ This is false. The premise of prevention is simply that it is better not to start using illegal drugs, and if now using, to stop.

Finally, harm reduction supporters continually point to parts of Europe as exemplars of the superiority of harm reduction. ${ }^{2-4}$ Yet, the Hassela Nordic Network (a "politically and religiously independent network for international exchange of theoretical ideas and suggestions for practical action to maintain a restrictive drugs policy") reports ongoing problems wherever harm reduction has been adopted, including increased drug production, creation of drug havens, drug tourism, failure of needle parks and coffee houses, and increases in both drug trafficking and in the incidence of cannabis and other "soft" drug use among youth. Clearly, much of the information we are being told about harm reduction in Europe is biased in favour of harm reduction.

The following are several steps we can take to back away from the precipice of retreat and rationalization offered by harm reduction:

1. We should stop using harm reduction to describe Canada's overall drug response. The term has become a code word for gross drug law reform and no such philosophical change can occur without at the least a very open public debate and decision. Anything less is dishonest and deceitful. The quiet foisting of harm reduction onto society needs to stop.

2. We should confirm clearly that illegal drug use is considered neither positive nor viable in the long term. Swedish drug policy offers a useful template: ${ }^{11}$ "A drug-free society is a high objective expressing society's attitude to narcotic drugs. We do not accept the integration of narcotic drugs in society, and our aim is a society in which drug use remains a marginal phenomenon." (ref.11, p. 1)

3. We should commit to do whatever it takes to help addicted persons get off drugs and become sufficiently rehabilitated to stay off them. Much more can be done in this regard.

4. We must stop paying lip service to, and start being serious about, prevention. Comprehensive and sustained prevention - not harm reduction provides a unifying concept broad and inclusive enough to envelop drug policy.

Policy characterized by these attributes offers a vision and longsightedness not possible with harm reduction. It tells present 
and future generations that drugs need never play a role in life. This is where our collective energy and intelligence need to be directed.

\section{REFERENCES}

1. Single E. Defining harm reduction. Drug and Alcohol Review 1995;14:287-90.

2. Erickson PG. Introduction: The three phases of harm reduction. An examination of emerging concepts, methodologies, and critiques. Substance Use and Misuse 1999;34:1-7.

3. Erickson PG, Riley DM, Cheung YW, O'Hare PA (Eds). Harm Reduction: A New Direction for Drug Policies and Programs. Toronto: University of Toronto Press, 1997.

4. Cheung YW. Substance abuse and developments in harm reduction. CMAJ 2000;162:1697-700.

5. Hankins C. Substance use: Time for drug law reform. CMAJ 2000;162:1693-94.

6. Riley D. The Harm Reduction Model: Pragmatic Approaches to Drug Use from the Area Between Intolerance and Neglect. Ottawa: Canadian Centre on Substance Abuse, 1994.

7. Health Canada. Canada's Drug Strategy. Ottawa: Minister of Public Works and Government Services Canada, 1998.

8. Roberts LJ, Marlatt AG. Harm reduction. In: Ott PJ, Tarter RE, Ammerman RT (Eds), Sourcebook on Substance Abuse: Etiology, Epidemiology, Assessment, and Treatment. Boston, MA: Allyn and Bacon, 1999; 389-98.

9. Mangham C. Tobacco reduction: A continued health promotion challenge. Can J Public Health 1999;90(2):77-79.

10. Kemeny A, Tremblay S. Drinking and driving: Have we made progress? Canadian Social Trends 1998;49:20-25.

11. National Institute on Health, Sweden. A Restrictive Drug Policy: The Swedish Experience. Stockholm: Grafiska Gruppen, 1993.

\section{AVAILABLE FROM CPHA'S HEALTH RESOURCES CENTRE}

\section{Air Quality Guidelines Air ruality Guidelines for Europe Second edition \\ for Europe \\ Second Edition}

WHO Regional Publications, European

Series, No. 91

2000, $x+273$ pages $[E]$

Order no. 1310091

$\$ 131.65$

Provides air quality guidelines for 35

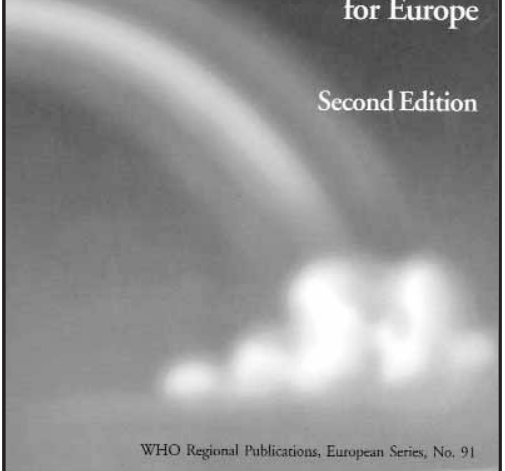

substances known to contribute to the problem of air pollution in

Europe. First issued in 1987, the book has been considerably updated and expanded in line with new research findings and advances in the methodology of risk assessment. Guideline values, which were revised in a series of expert consultations, are intended to serve as a basis for the establishment of national standards and other control measures needed to safeguard public health.

The book has three parts. The first outlines the methodological problems involved in assessing the health risks posed by air constituents and contaminants, whether in indoor or outdoor air. Readers are also given a summary of the criteria used in establishing guideline values for both carcinogenic and noncarcinogenic substances and for estimating ecological effects. Part one concludes with advice on use of the guidelines to protect public health.

The second and most extensive part presents guideline values for 16 organic pollutants, 12 inorganic pollutants, 4 classical pollutants, and 3 indoor air pollutants, namely tobacco smoke, man-made vitreous fibres, and radon. Each guideline value is supported by a summary of available data on typical concentrations and levels of exposure, and the effects on human health. The final part considers the ecotoxic effects of selected inorganic substances, and includes an explanation of the complex type of air pollution that can damage crops, tree species, and other vegetation.

Order today from the CPHA Health Resources Centre 400-1565 Carling Avenue, Ottawa, ON K1Z 8R1

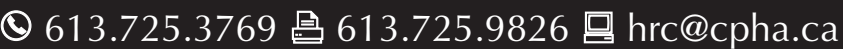

